\title{
Divorce Risk Factors Across Finnish Marriage Cohorts, 1954-1989
}

\author{
JUHO HÄRKÖNEN, M.Sc., Visiting Pre-Doctoral Fellow \\ The Malcolm Wiener Center for Social Policy \\ JFK School of Government \\ Harvard University, USA
}

\begin{abstract}
This paper examines whether there has been a change in the effects of three divorce risk factors, female educational attainment, cohabitation, and parity. Several theoretical reasons suggest such a change, but the existing evidence gives mixed results. First marriages of Finnish women married between 1954 and 1989 are analysed using data from the Fertility and Family Surveys (FFS), collected in 1989 and 1990. The results from the discrete-time event history models show that the effect of having children on marital stability has changed: the impact of having two children has become less evident, while the effect of having three children or more has increased. These trends hold after controlling for young children and premarital children. Some explanations for this shift are discussed.
\end{abstract}

Keywords: divorce, education, cohabitation, parity, change, event-history models

\section{Introduction}

The increase in marital dissolution rates has been one of the most visible and pronounced features of the change in the Western family institution. This increase has been attributed to various social transformations, such as cultural change, the changing socioeconomic role of women, and "modernization" as a more all-encompassing development (e.g., Becker, Landes and Michael 1977; Goode 1970; Lesthaeghe 1995). In Finland, divorce rates increased throughout the 20th century and currently they are among the highest in Europe (Jalovaara 2000; Lutz, Wils and Nieminen 1992; Figure 1). This increase has been mainly interpreted in terms of period effects (Lutz et al. 1992). One of the specific events affecting Finnish divorce rates was the liberalization in the divorce laws in 1987, and, indeed, Figure 1 presents a related acceleration in divorce rates between 1985 and 1990. 
Figure 1. Divorce risk trends in Finland, Sweden, the UK, Germany and Italy, 1960-2000.

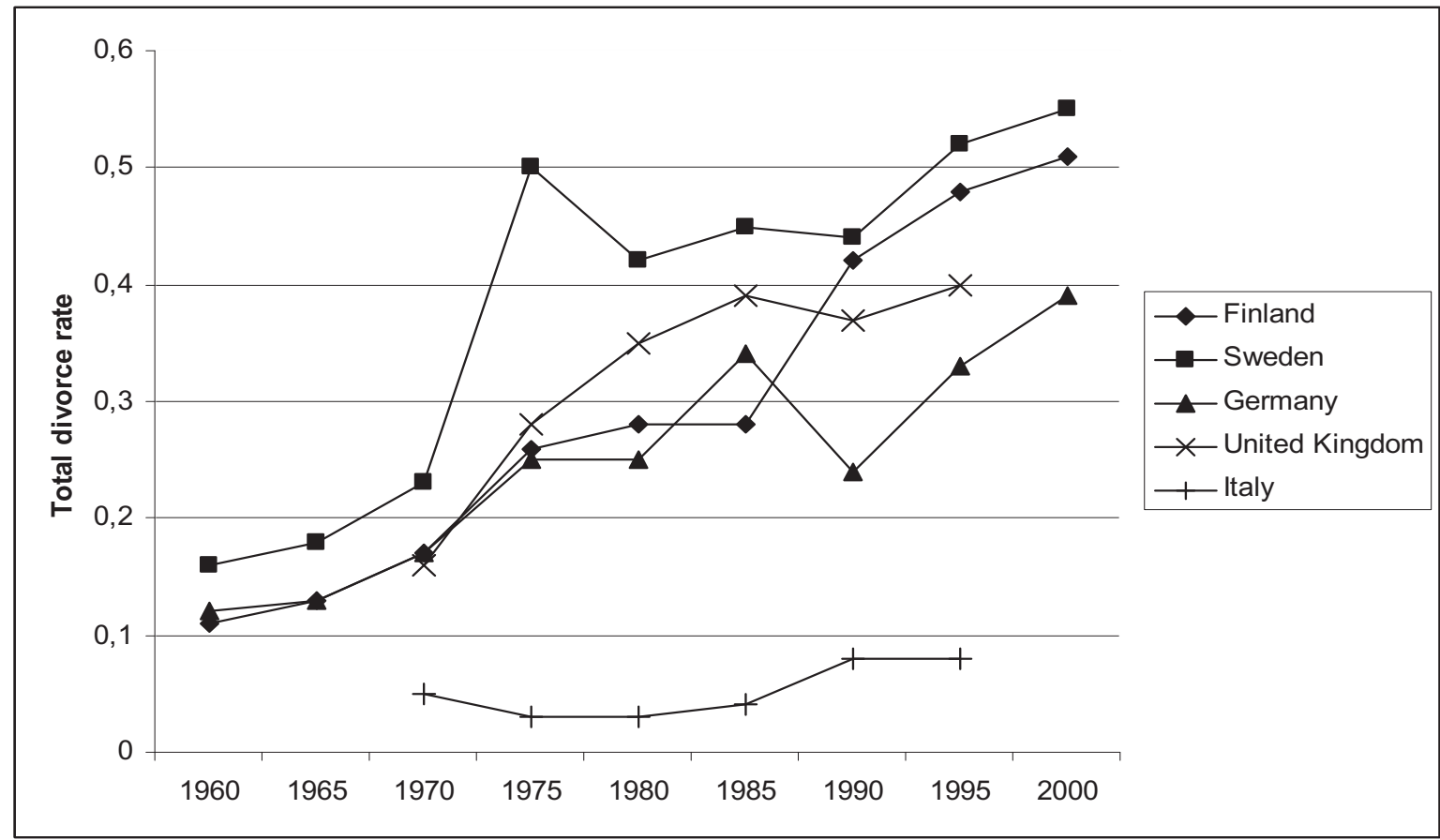

Source: Council of Europe (2001) Recent Demographic Developments in Europe

Apart from studying the factors responsible for the increase in the overall levels of marital disruption, the divorce literature has identified several individual and family level risk factors (Andersson 1995; Berrington and Diamond 1999; Bumpass and Sweet 1972; Diekmann and Klein 1991; White 1990). Finnish research on the social and demographic aspects of divorce has found that low socio-economic status (with the exception of the income of the wife), low age at marriage, and premarital cohabitation increase the risk of divorce, while divorce is less common among the Swedish-speaking population, among couples with (especially small) children and among couples with well-earning husbands (Lutz et al. 1992; Finnäs 1996; 1997; Jalovaara 2000; 2001; 2003). These results resemble those from Scandinavian and American studies.

Whereas much interest has been given to the macro-level changes in divorce rates on the one hand, and the micro-level risk factors on the other, previous research has focused far less on the question of changes in the effects of the risk factors over time. The implicit underlying assumption behind most research on divorce risks is that the effects of the independent variables have remained stable (Teachman 2002). There are, however, good reasons to assume that the effects of individual and family level factors might well have changed over time. The predominant theories of divorce all assume that a couple divorces when the real or perceived well-being (material and/or expressive) of the outside option exceeds that of the partnership (Becker et al. 1977; Levinger 1976; Oppenheimer 1997; Teachman 2002, 331-2). These utilities are determined not only by the partnership itself, but also by the opportunities outside 
marriage (e.g., re-marriage, economic prospects) and the costs involved with dissolving the marriage (e.g., legislation, economic costs, social costs). Since both the quality of partnerships and the opportunities and costs linked with marriage dissolution can vary across social groups, their divorce risk can also be assumed to vary (as supported by empirical research). It is, further, plausible to expect that the changes in family systems and their social environments have not affected all social groups in a similar way, thus leading to differences in the effects of divorce risk factors over time.

This paper analyses whether the effects of female educational attainment, premarital cohabitation, and children have changed across first marriage cohorts in Finland. The choice of the background factors is based on theoretical, social and practical concerns. These factors have been of interest for many previous studies on divorce, both theoretical and empirical. As cohabitation has become more popular, many studies have asked whether the increase in cohabitation is somehow related to the increase in divorce rates. The effects of education and children are not only interesting from a theoretical point of view, but questions of their effects have been in the forefront of the concerns of the social inequality effects of divorce (e.g., McLanahan 2004). Other interesting factors, such as female labour market activity and success (Jalovaara 2001; South 2001) were omitted due to data restrictions (retrospective data, such as those used in this paper, are not ideal for measuring labour market activity and human capital accumulated in the labour market). The data come from the Fertility and Family Survey, a retrospective survey of family histories, which was collected in 1989 and 1990. They include retrospective information on the life histories of women born between 1938 and 1967. Although the data are not fully up-to-date, they cover a period of rapid change in the Finnish society and family institution. Therefore, they enable analysis of historical changes in the effects of divorce risk factors, and provide a background for analysis of more recent divorce patterns.

\section{Instability of divorce risk factors?}

As discussed in the Introduction, several theoretical arguments suggest that the effects of various divorce risk factors may have changed. First of all, the benefits of staying in a particular marriage contra the costs and benefits of divorce may have changed differently in different social groups. For example, in an early paper, William Goode (1962) argued that while in earlier periods, divorce was the privilege of the well-off, the decreasing costs of divorce make it more accessible to the lower social groups, so that in the end it may be these groups (with higher marital strain) who divorce more. Teachman (2002) generalized this argument by arguing that when divorce is difficult, any factors related positively to divorce will be suppressed. That is, their impact comes apparent only when the barriers to divorce are lower. Similar arguments of the changing costs and benefits of divorce have been used to explain the increasingly positive effects of the employment of wives on the risk of divorce in the United States (South 2001). 
The relationship between risk factors and divorce can also change because of changes in the composition of social groups, or because of the unequal diffusion of social practices (Chan and Halpin 2005). Chan and Halpin use cohabitation as an example of the compositional (or selection) effect (discussed more below). In these cases the change in the relationship between divorce and the factor of interest is due to a change in the social selection process into the group of interest (which makes talking about effects in any causal sense problematic). The latter hypothesis suggests that one's social network may have an effect on one's attitudes and behaviour through information and social pressure. Behavioural patterns can also spread across social boundaries, indeed, it is often assumed that behaviours "trickle down" from the higher social groups. Demographic behaviour, which at one point in time is practiced only by the upper classes, may later become normal throughout the social spectrum. Next, hypotheses suggesting changes in the effects of educational attainment, premarital cohabitation, and children are discussed in more detail.

Education: According to the economic theory of the family, wife's education improves her economic opportunities outside marriage and decreases the mutual interdependence between the partners (Becker et al. 1977). Educated women may also possess skills needed to handle the divorce process, and hold more liberal values (Blossfeld et al. 1995; Levinger 1976). These factors suggest a positive effect of female education on the risk of divorce. On the other hand, education can positively affect marital matching, improve communication and social skills, and lessen marital strain due to economic factors (Amato 1996; Hoem 1997; Ono 1998; Oppenheimer 1997), which would suggest a negative effect. Previous research on the effects of education on divorce in Finland suggests that the negative effects are stronger, i.e. higher education is associated with a lower risk of divorce. However, following the hypothesis introduced above (Goode 1962), the net effect may have become negative only recently. Furthermore, following the dramatic improvement of women's educational qualifications under the period of study, the attractiveness of highly educated women may have increased, as suggested by Finnäs's (1995) results on union formation. For Britain, Chan and Halpin (2005) reported that the effect of education has indeed changed from a positive to a negative one. Härkönen and Dronkers (2005) found that the relationship between female education and union disruption has turned negative in some countries, to a certain extent also in Finland. Teachman (2002) did not find changes in the educational gradient of divorce in the US.

Premarital cohabitation: The positive relationship between premarital cohabitation and divorce found in many studies can be mainly explained by social selection: those cohabiting before marriage hold more liberal values, and for the same reason they also divorce more. We can expect that the relationship between cohabitation and divorce becomes weaker as cohabitation becomes more popular, both because selection into 
cohabitation decreases, and because the normalization of cohabitation decreases the social pressure on cohabiting couples. However, when those traditional couples who marry directly become the selective minority, the relationship between cohabitation and divorce may become more positive again (Chan and Halpin 2005; Hoem and Hoem 1988 in Finnäs 1995, 22).

In Finland, cohabitation became more popular in the 1960s, and by the 1980s, only a minority of unions began directly as marriages (Lindgren, Ritamies and Miettinen 1992). At the same time, cohabitation periods became longer. However, at least up to the early 1990s, most consensual unions ended either in marriage or dissolution, and cohabitation as a permanent life-style choice was rare.

Consensual unions and marriages starting as consensual unions have a higher disruption rate than unions starting as marriages (Finnäs 1996). For the UK, Chan and Halpin (2005) found a U-shaped curve on the relationship between premarital cohabitation and divorce over time: first a strong positive relationship, then a decrease followed by a slight reversal of the trend. Finnäs (1996) did not find that an inclusion of an interaction term between cohort and premarital cohabitation significantly improved his models for Finnish data. Hoem and Hoem (1988, see Finnäs 1995, 22) found that in Sweden, unions starting directly as marriages had decreasing divorce rates, which was in sharp contrast with the otherwise increasing dissolution patterns.

Children: According to economic theory, common children are a relationship specific investment which stabilizes marriages (Becker et al. 1977). Children are also a positive signal of the quality of the marriage. Most studies have found general evidence for the hypotheses of a stabilizing effect of children (Andersson 1997; Lutz 1993). However, some recent studies have reported that divorce has become more common among couples with many children (e.g., Chan and Halpin 2005). This suggests that the impact of children is not straightforward. First, apart from parity, the age of the youngest child has been shown to have an effect on divorce, so that children under school-age (and, in particular very small children) have a stabilizing effect on marriages (e.g., Andersson 1997). Second, the increase in premarital childbearing has increased the number of families with stepchildren, where it has been shown that stepchildren receive less parental investment than biological children (Case, Lin and McLanahan 2000): therefore the stabilizing effect should decrease. It can also be the case that children born within the same union, but before marriage may have a destabilizing effect. These children are more likely to be unplanned or the parents may otherwise have less commitment to them. On the other hand, children born before marriage are older than other children, and therefore the relationship may disappear by controlling for the age of the youngest child. However, premarital children seem to explain the result of a reversal in the association between children and divorce in the UK in the 
few last decades (Chan and Halpin 2005). Third, divorce risks at different parities may have changed at a different pace. As the average number of children in a family changes, those having more or less children than the average may form a selective group according to marital commitment, values, and the like (cf. Andersson 1997).

\section{Data and variables}

The data come from the Fertility and Family Survey (FFS), co-ordinated by the Population Activities Unit of the United Nations Economic Council for Europe. The data, collected in Finland in 1989 and 1990, include the marital histories of women born between 1938 and 1967 (first married between 1954 and 1989).

Table 1. Basic information on the sample.

\begin{tabular}{lrr}
\hline & $\mathrm{n}$ & $\%$ \\
\hline Divorces & 333 & 1.5 \\
Marriage cohort 1956-61 & 1,470 & 6.0 \\
Marriage cohort 1962-67 & 5,213 & 21.2 \\
Marriage cohort 1968-73 & 7,745 & 31.5 \\
Marriage cohort 1974-79 & 6,386 & 26.0 \\
Marriage cohort 1980-86 & 3,745 & 15.3 \\
Low education (ISCED 0-2) & 4,107 & 16.9 \\
Middle education (ISCED 3) & 16,236 & 65.3 \\
High education (ISCED 4-6) & 4,457 & 17.8 \\
Pre-marital cohabitation & 9,337 & 37.1 \\
Parity 0 & 5,046 & 19.8 \\
Parity 1 & 8,743 & 35.3 \\
Parity 2 & 8,458 & 34.5 \\
Parity 3+ & 2,556 & 10.4 \\
Children <2 years & 7,477 & 30.1 \\
All extra-marital children & 1,401 & 5.5 \\
Parental divorce & 1,363 & 5.5 \\
& & \\
& & Mean \\
\hline Age at marriage (mean) & 22.4 & 3.4 \\
Duration at divorce (mean) & 7.1 & 3.6 \\
N Women & & \\
Person-years & 2,373 & \\
\hline
\end{tabular}

Source: Fertility and Family Survey, the Finnish sub-sample, author's own calculations 
The final number of women included in the analyses is 2,373 (see Table 1). The analyses are restricted to first marriages of women who were aged 17 years or more at the time of marriage and who gave full information on all the variables. The primary time variable is the year of marriage. The educational attainment variable is time-dependent, that is, its values may vary for individuals across time. It is classified in three categories according to the ISCED-scale, low (ISCED 0-2), middle (ISCED 3), and high (ISCED 4-6). The cohabitation variable indicates whether the respondent has ever cohabited before the marriage (it is possible that the respondent has cohabited with another man before the marriage). Previous cohabitation and cohabitation with the husband overlapped strongly, and therefore only one measure was used. The primary child variable of interest is parity, which is split into parities zero, one, two, and three and above. Using an alternative variable which, in addition to parity, included the children brought by the husband into the household did not affect the results.

Apart from these variables of primary interest, the models include the following variables: duration (linear and quadratic terms), parental divorce (an effect has been reported in many studies and parental divorce may also affect the factors of interest (Amato 1995; Ermisch, Francesconi and Pevalin 2004)), and age at start of marriage (young age at marriage has generally been found to be detrimental for the stability of the marriage). Since marital duration is included in the models, the effects of the year of marriage can also be interpreted as period effects (Teachman 2002), an interpretation which is in line with previous results stressing the prevalence of period effects over cohort effects (Lutz et al. 1991).

The method used for analysis is discrete-time event history analysis (Yamaguchi 1991), with one year as the basic unit of time. ${ }^{1}$ Due to the possibly selective nature of very long lasting marriages, spells lasting over fifteen years were treated as right-censored. Event-history analysis is optimal for handling data with time-varying covariates and rightcensored episodes (the ending times of spells are not observed). Discrete-time models were chosen instead of continuous-time models, since they can handle ties (simultaneous events) more efficiently, and the coding of time-varying covariates is easier than with continuous-time models. Parameter estimates are shown as odds ratios $(\exp (\beta))$.

The analyses proceed as follows. First, the results of the bivariate relationships between the covariates and the risk of divorce are presented (Table 2). The same table shows the coefficients of the baseline model. The baseline model includes the linear and quadratic terms of duration, the age at start of marriage, parental divorce, linear term of the year of marriage, educational attainment, and parity. Next, Table 3 presents

\footnotetext{
${ }^{1}$ Year instead of month was chosen due to practical reasons. The models with personmonths returned very much the same results, with differences mainly in the second decimal.
} 
model comparisons between the baseline model and models with linear interactions between the variables of interest and the year of marriage. The best models are then examined more closely.

\section{Results}

The first column in Table 2 shows results from the bivariate models, where each risk factor was entered separately. The coefficient estimates show a familiar pattern with a negative relationship between divorce, educational attainment, and age at marriage, whereas parental divorce, later year at marriage and premarital cohabitation are associated with a higher risk of divorce. The association between parity and divorce risk is less straightforward, with a significant association being found for women with three or more children.

Table 2. Bivariate effect and main effect models on the risk of divorce.

\begin{tabular}{lcc}
\hline & Bivariate model & Baseline model \\
\hline Duration & $1.365^{* *}$ & $1.543^{* *}$ \\
squared & $0.981^{* *}$ & $0.977^{* *}$ \\
Age at marriage & $0.915^{* *}$ & $0.901^{* *}$ \\
Parental divorce & $1.465 \dagger$ & $1.445 \dagger$ \\
Middle education (Ref: low) & $0.759^{*}$ & $0.712^{*}$ \\
High education & $0.619^{*}$ & $0.662^{*}$ \\
Cohabit with someone & $1.450^{* *}$ & $1.338^{*}$ \\
One child (Ref: no kids) & 1.044 & $0.710^{*}$ \\
Two children & 0.873 & $0.466^{* *}$ \\
Three or more children & $0.564^{*}$ & $0.289^{* *}$ \\
Year of marriage & $1.014 \dagger$ & $1.028^{*}$ \\
Log-likelihood & & -1710.690 \\
$X^{2}$ & & 110.97 \\
$d f$ & & 11 \\
Person-years & & 24803 \\
Divorces & & 333 \\
\hline
\end{tabular}

†p<0.10; ${ }^{*}<<0.05 ;{ }^{* *} p<0.01$

${ }^{1}$ The baseline model includes the linear and quadratic terms of duration of marriage, the age at start of marriage, parental divorce, linear term of the year of marriage, educational attainment, and parity

The next column presents the baseline model, which includes the variables of most interest and the controls. The coefficient estimates remain rather similar, with cohabitation losing in significance, while the effects of parity levels become more visible. In addition, a model was tested where the linear term of the year of marriage was replaced by a categorical marriage cohort variable $(1956-61 ; 1962-67 ; 1968-73 ; 1974-79$; 1980-86). The cohorts were made to include reasonable numbers of divorces in each category, therefore the youngest and the oldest years of marriage were left out. The results remained very similar. The youngest cohort had the strongest (positive) effect. 
Have these effects changed through time, as various theoretical positions and some empirical results would suggest? Table 3 shows the results obtained by models including an interaction term between the linear term of year of marriage and the independent variable of interest. Model comparisons are done with the traditional likelihood-ratio tests and the Bayesian Information Criterion (BIC) statistic (Raftery 1995). The latter statistic is better for comparing non-nested models. The smaller the value of the BIC, the better the fit, and the better the model is in terms of parsimony.

Table 3. Comparing the baseline model ${ }^{1}$ with models including interactions between the linear effect of the year of marriage and the covariates.

\begin{tabular}{lccccc}
\hline Model & $\begin{array}{c}\text { Log- } \\
\text { likelihood }\end{array}$ & $\begin{array}{c}\mathrm{p}(\mathrm{i} \text { vs. } \\
\text { baseline })\end{array}$ & $\chi^{2}$ & $\mathrm{df}$ & $\mathrm{BIC}$ \\
\hline A: Baseline & -1710.690 & - & 110.97 & 11 & -47.08 \\
B: A + year*education & -1709.870 & 0.440 & 112.61 & 13 & -37.10 \\
C: A + year*middle educ. & -1709.872 & 0.201 & 112.61 & 12 & -42.91 \\
D: A + year*high educ. & -1710.446 & 0.484 & 111.46 & 12 & -41.76 \\
E: A + year*cohabitation & -1709.546 & 0.130 & 113.26 & 12 & -43.56 \\
F: A + year"parity & -1707.038 & 0.063 & 118.28 & 14 & -36.97 \\
G: A + year*parity=1 & -1710.255 & 0.351 & 111.84 & 12 & -42.14 \\
H: A + year*parity=2 & -1708.453 & 0.034 & 115.45 & 12 & -45.75 \\
I: A + year*parity=3 & -1708.713 & 0.047 & 114.93 & 12 & -45.23 \\
J: A + year*educ., coh., par. & -1705.438 & 0.162 & 121.48 & 18 & -16.93 \\
\hline
\end{tabular}

${ }^{1}$ The baseline model includes the linear and quadratic terms of duration, the age at start of marriage, parental divorce, linear term of the year of marriage, educational attainment, and parity

In model $\mathrm{B}$, both the education dummies are entered at once, while in models $\mathrm{C}$ and $\mathrm{D}$, the dummies are entered separately. The results do not support the hypothesis of a change in the educational gradient of divorce. This result differs from that found by Härkönen and Dronkers (2005), who reported a small negative trend. However, their model was differently specified (as the core interest was in the effects of education), and it took into account all relationships, not just marriages. Also the test for a change in the effects of cohabitation before marrying (model E) does not support the change hypothesis. This result differs from that reported by Chan and Halpin (2005) for the UK. To test for a possible curvilinear change in the effects of cohabitation, as suggested by some hypotheses, an interaction term was included between a squared term of year at marriage and cohabitation, but this experiment did not give reasons to prefer that model to the baseline one.

Models F to I test for a change in the effects of children, first with all the parity-dummies entered at once, and then one at a time. According to the likelihood-ratio test, Model $\mathrm{F}$ fits the data best, and the difference is nearly significant at the 5 percent level, thus suggesting that the effect of children has changed over time (cf. Chan and Halpin 2005). The BIC-statistic does not, however, favor this model. According to models 
$\mathrm{G}$ to $\mathrm{I}$, it seems that there has been a change in the effects of having two children and in the effects of having three or more children. Even though the BIC-statistics would still favor the baseline model, the support from the likelihood-ratio test seems strong enough to point to a change in the effects of parities two and three plus. In Model J, all the two-way interactions are entered. The fit statistics do not support the model.

Table 4. Models $\mathrm{H}$ and I with controls.

\begin{tabular}{|c|c|c|c|c|c|c|}
\hline & $\begin{array}{l}\text { Model H } \\
\text { (parity 2) }\end{array}$ & +small child & $\begin{array}{c}\text { +extra-marital } \\
\text { child }\end{array}$ & $\begin{array}{c}\text { Model I } \\
\text { (parity 3+) }\end{array}$ & +small child & $\begin{array}{c}\text { +extra-marital } \\
\text { child }\end{array}$ \\
\hline $\begin{array}{l}\text { Parity }{ }^{*} \\
\text { Year of } \\
\text { marriage }\end{array}$ & $1.042 *$ & 1.044 * & $1.040 *$ & $0.937 \dagger$ & $0.941 \dagger$ & $0.937 \dagger$ \\
\hline $\begin{array}{l}\text { Child }<2 \\
\text { years }\end{array}$ & & $0.441^{* *}$ & & & 0.450 ** & \\
\hline $\begin{array}{l}\text { Extra- } \\
\text { marital } \\
\text { child }\end{array}$ & & & $2.033^{* *}$ & & & $2.064^{* *}$ \\
\hline $\begin{array}{l}\text { Log- } \\
\text { likelihood }\end{array}$ & -1694.22 & -1681.82 & -1688.71 & -1694.73 & -1682.97 & -1688.99 \\
\hline $\begin{array}{l}d f \\
X^{2}\end{array}$ & $\begin{array}{c}12 \\
111.54\end{array}$ & $\begin{array}{c}13 \\
136.33\end{array}$ & $\begin{array}{c}13 \\
122.55\end{array}$ & $\begin{array}{c}12 \\
110.52\end{array}$ & $\begin{array}{c}13 \\
134.04\end{array}$ & $\begin{array}{c}13 \\
121.99\end{array}$ \\
\hline
\end{tabular}

$\dagger p<0.10 ;{ }^{*} p<0.05 ;{ }^{* *} p<0.01$

According to Table 3, there has only been change in the effects of having two children or more (Models H and I). In Table 4, these models are examined more closely. For both models, parameter estimates are first shown for the interaction between parity and the linear term of the year of marriage. It seems that the effect of having two children has become more positive, while the effect of having three or more children has become more negative. In the second columns, the presence of a small child (under 2 years old) is included in the model, in order to test whether the change in the effects of the parities is caused by changes in the probabilities of having small children in the household. The age threshold was chosen on the basis of preliminary testing with two-year age categories, in which the chosen category turned out to be the only one with a statistically significant effect on the risk of divorce (cf. Lutz 1993). When this variable was added in the baseline model, the child effects decreased (results not shown). However, as can be seen from Table 4, adding the small child variable does not have an effect on the interaction terms, and small children therefore do not appear to explain the change. Next the presence of extramarital children (whether within or outside the union) is added in the model. While couples with extramarital children have a higher risk of divorce, this variable does not seem to explain the change either (unlike with Chan and Halpin 2005). The conclusion does not change, even if both variables are entered simultaneously (not shown). It thus seems that there has been a genuine shift in the effects of having two or more children. Somewhat similar changes were, in fact, reported by Andersson (1997) for Sweden. 
Figure 2 presents these patterns by looking at the effects of parity two and three plus across the above-mentioned five marriage cohorts. The estimates come from the baseline models estimated separately within each cohort. However, the reference category for parity is no children or one child. These categories were collapsed into one because of the few marriage-years and events in the childless category in some of the cohorts. When the variables "young child" and "extramarital" child are included in the model, the results remain similar, with some changes in significance levels but less important changes in the parameter estimates (not shown). However, the baseline model can be preferred in order to maximize efficiency when using cohorts with a limited number of events.

Figure 2. Changes in the effects of parities two and three plus on divorce, odds ratios (reference: no children or one child).

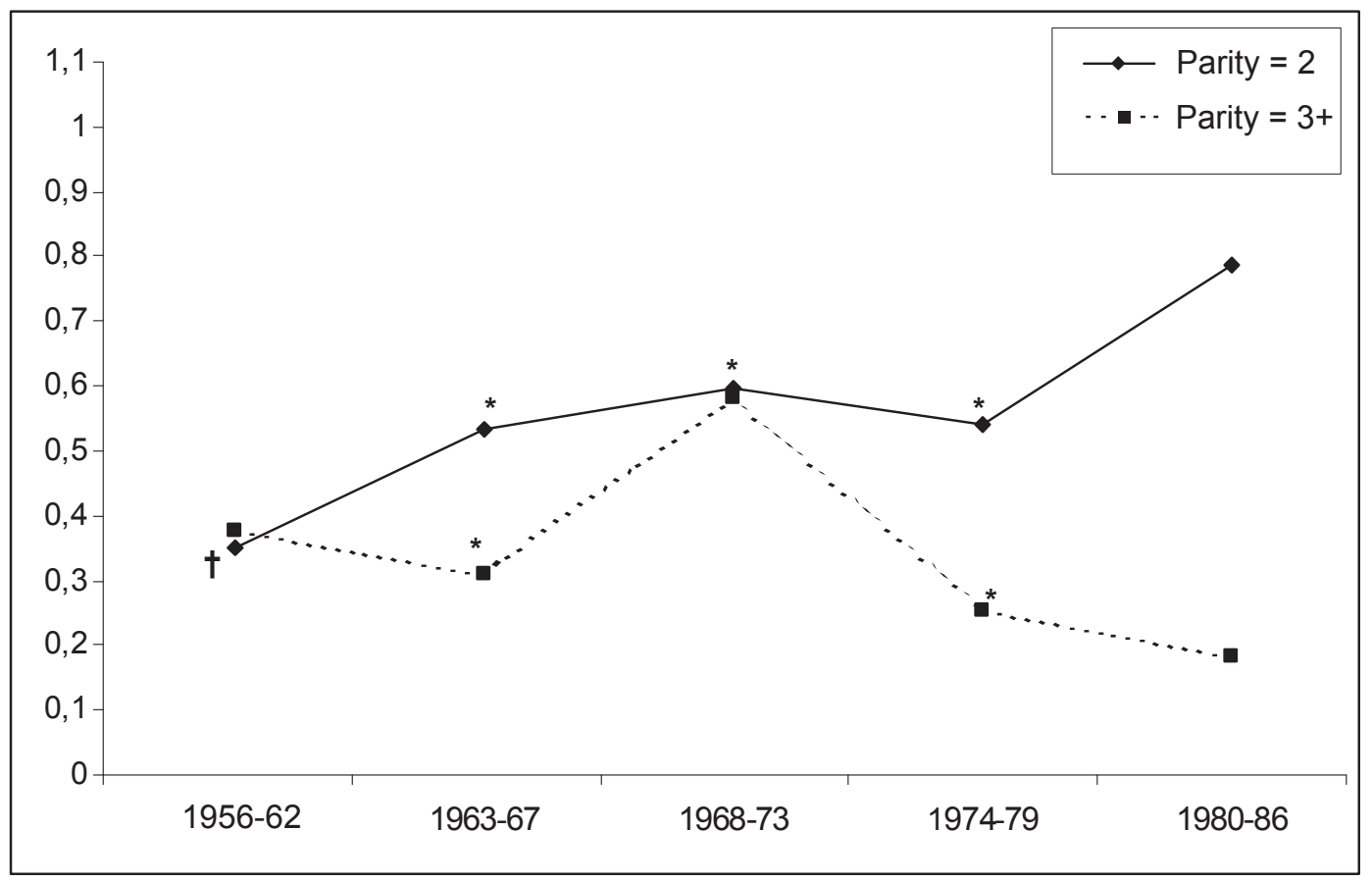

$\dagger p<0.10 ;{ }^{*} p<0.05 ;{ }^{* *} p<0.01$

In Figure 2 we can detect a rather clear trend towards less negative effects of parity two. In the youngest cohort, the estimate for parity two is already insignificant and close to one. There is also a less clear trend towards more negative effects of parity three and above. Figure 2 seems to support the results from Tables 3 and 4 , in particular in the case of parity two. Therefore, it seems that there really has been a shift in the effects of the number of children. 


\section{Discussion}

This paper has tested the hypothesis of a change in the effects of divorce risk factors over time in Finland with data (collected in 1989 and 1990) on the first marriages of Finnish women married between 1954 and 1989. Focusing on the effects of educational achievement, extramarital cohabitation, and number of children, a change was observed towards a less negative effect of having two children and towards a more negative effect of having three or more children on the risk of divorce. These changes were not explained by the inclusion of young children or extramarital children in the model. Thus, it seems that there has been a genuine shift in the impact of the number of children on marital stability. For the other risk factors, the change hypothesis was not supported.

In a general sense, therefore, the conclusions drawn from these results are similar to those found by Teachman (2002) for the US: there has mostly been relative stability over time. At the same time, these results are in contrast with those reported by Chan and Halpin (2005) for the UK, except for the effects of parity. These results suggest that unlike before, divorce is becoming relatively more common among families with two children, and relatively less common among couples with three or more children. What could explain these changes? Because of the opposite trends in the effects of the different parities, economic theory is unlikely to offer much help. The explanation may be related with the change in the average number of children, and the selection into different parities. It can be assumed that as the average number of children has decreased, those couples with more than two children may include an increasing proportion of couples positively selected according to marital stability (values, commitment to family versus work, etc.). On the other hand, the decrease in the stabilizing effect of having two children is harder to explain. This may also have to do with changing fertility rates, as the average number of children born to a woman has decreased below two. Despite the prevailing two-child norm, the "one-point-something" fertility rates may reflect new preferences for the number of children, which also shape the effects of children on divorce.

These results provide an interesting first glimpse into the (in)stabilities of divorce risk factors in Finland. However, in contrast to the papers by Teachman (2002) and Chan and Halpin (2005), this study has to cope with the limitations of a sample of a very moderate size. Thus, a replication of the analyses with a bigger sample would be welcome. The sample was collected fifteen years ago, and although it gives a picture of the period ranging roughly from the late fifties to the late eighties, a reanalysis of these questions with fresher data would be of clear interest, especially knowing the increases in divorce and the major socio-economic changes that have taken place since the early 1990s. 


\section{Acknowledgments}

The author wishes to thank Jani Erola, Jaap Dronkers, Martin Kohli and an anonomous referee for valuable comments. Tak Wing Chan kindly gave permission to refer to their yet unpublished results. The research was supported by the Academy of Finland (grant number 205228).

\section{References}

Amato, Paul. 1996. Explaining the intergenerational transmission of divorce. Journal of Marriage and the Family 58(3):628-640.

Andersson, Gunnar. 1995. Divorce-risk trends in Sweden 1971-1993. European Journal of Population 11(4): 293-311.

---. 1997. The impact of children on divorce risks of Swedish women. European Journal of Population 13(2):109-145.

Becker, Gary S., Elizabeth M. Landes and Robert T. Michael (1977) An economic analysis of marital instability. Journal of Political Economy 85(6):1141-1187.

Berrington, Ann and Ian Diamond. 1999. Marital dissolution among the 1958 British birth cohort: The role of cohabitation. Population Studies 53(1):19-36.

Blossfeld, Hans-Peter, Alessandra de Rose, Jan M. Hoem and Götz Rohwer. 1995. Education, Modernization, and the Risk of Marriage Disruption in Sweden, West Germany, and Italy. In: Gender and Family Change in Industrialized Societies, edited by Karen Oppenheim Mason and An-Magritt Jensen, pp. 200-222. Oxford: Clarendon Press.

Bumpass, Larry L. and James A. Sweet. 1972. Differentials in Marital Instability: 1970. American Sociological Review 37(6):754-766.

Case, Anne, I-Fen Lin and Sara McLanahan. 2000. How hungry is the selfish gene? The Economic Journal 110(October):781-804.

Chan, Tak Wing and Brendan Halpin. 2005. The instability of divorce factors in the UK. Unpublished paper, March 2005. Oxford: University of Oxford.

Diekmann, Andreas and Thomas Klein. 1991. Bestimmungsgründe des Ehescheidungsrisikos. Eine empirische Untersuchung mit den Daten des Sozioökonomischen Panels. Kölner Zeitschrift für Soziologie und Sozialpsychologie, 43(2):271-290.

Ermisch, John, Marco Francesconi and David J. Pevalin (2004) Parental partnership and joblessness in childhood and their influences on young people's outcomes. Journal of the Royal Statistical Society. Series A (Statistics in Society) 167(1):69-102.

Goode, William J. 1962. Marital satisfaction and instability. A cross-cultural class analysis of divorce rates. In: Class, status, and power. Social stratification in comparative perspective, edited by Reinhard Bendix and Seymour Lipset, Pp. 377-387, New York: The Free Press.

---. 1970. World revolution and family patterns. New York:The Free Press.

Finnäs, Fjalar. 1995. Entry into Consensual Unions and Marriages Among Finnish Women Born Between 1939-1975. Population Studies 49(1):57-70.

---. 1996. Separations Among Finnish Women Born Between 1938-1967. Yearbook of Population Research in Finland 33:21-33.

---. 1997. Social Integration, Heterogeneity, and Divorce. The Case of the Swedish-speaking Population in Finland. Acta Sociologica 40(3):263-334.

Hoem, Britta and Jan Hoem. 1988. Dissolution in Sweden: The break-up of conjugal unions to Swedish women born in 1936-60. Stockholm Research Reports in Demography No. 45. Stockholm: University of Stockholm. 
Härkönen, Juho and Jaap Dronkers. 2005. Stability and change in the effects of female educational attainment and the risk of union dissolution. A Comparison of Seventeen Countries. Unpublished paper, May 2005. Florence: European University Institute.

Jalovaara, Marika 2000. Divorce by family composition and socioeconomic status in Finnish first marriages. Yearbook of Population Research in Finland 36:63-88.

---. 2001. Socio-economic status and divorce in first marriages in Finland 1991-93. Population Studies 55(2):199-33.

---. 2003. The joint effects of married partners' socioeconomic positions on the risk of divorce. Demography 40(1):67-81.

Lesthaeghe, Ron. 1995. The second demographic transition in Western societies: An interpretation. In: Gender and family change in industrialized societies, edited by Oppenheim Mason, Karen and An-Magritt Jensen, pp. 17-62. Oxford: Clarendon Press.

Levinger, George. 1976. A social psychological view on marital dissolution. Journal of Social Issues 32(1):21-42.

Lindgren, Jarl, Marketta Ritamies and Anneli Miettinen. 1992. Consensual unions and their dissolution among Finnish women born in 1938-1969. Yearbook of Population Research in Finland 30:33-43.

Lutz, Wolfgang. 1993. Effects of children on divorce probabilities and of divorce on fertility: The case of Finland 1984. Yearbook of Population Research in Finland 31:72-80.

---, Anne B. Wils and Mauri Nieminen .1991. The demographic dimensions of divorce. The case of Finland. Population Studies 45(3):437-453.

McLanahan, Sara. 2004. Diverging destinies. How children are faring under the second demographic transition. Demography 41(4):607-627.

Ono, Hiromi. 1998. Husbands' and wives' resources and marital dissolution. Journal or Marriage and the Family 60(3):674-89.

Oppenheimer, Valerie Kincade. 1997. Women's Employment and the Gain to Marriage. Annual Review of Sociology 23:431-453.

Raftery, Adrian E. 1995. Bayesian Model Selection in Social Research. Sociological Methodology 25:111-163

South, Scott J. 2001. Time-dependent effects of wives' employment on marital dissolution. American Sociological Review 66(2):226-245.

Teachman, Jay D. 2002. Stability across cohorts in divorce risk factors. Demography 39(2): 331-351.

White, Lynn K. 1990. Determinants of Divorce: A Review of Research in the Eighties. Journal of Marriage and the Family 52(4):904-912.

Yamaguchi, Kazuo. 1991. Event history analysis. Newbury Park, CA: Sage. 